\title{
Gastrointestinal parasites of dogs (Canis familiaris) in Maiduguri, Borno State, Northeastern Nigeria: Risk factors and zoonotic implications for human health
}

\author{
Kingsley Uwakwe Ezema ${ }^{1}$, Samson Anjikwi Malgwi ${ }^{2}$, Mohammed Kyari Zango ${ }^{2}$, Falmata Kyari², \\ Salamatu Mohammed Tukur², Ali Mohammed² and Babagana Kachalla Kayeri² \\ 1. Veterinary Teaching Hospital, University of Maiduguri, Borno State, Nigeria; 2. Department of Veterinary Parasitology \\ and Entomology, Faculty of Veterinary Medicine, University of Maiduguri, Borno State, Nigeria. \\ Corresponding author: Samson Anjikwi Malgwi, e-mail: samsonmalgwi@unimaid.edu.ng \\ Co-authors: KUE: kuwakwe8@gmail.com, MKZ: mkzango@yahoo.com, FK: drfkyari@gmail.com, \\ SMT: salmatukur@yahoo.com, AM: vetmadeali@gmail.com,BKK: kayerima@gmail.com \\ Received: 10-03-2019, Accepted: 10-06-2019, Published online: 28-07-2019
}

doi: 10.14202/vetworld.2019.1150-1153 How to cite this article: Ezema KU, Malgwi SA, Zango MK, Kyari F, Tukur SM, Mohammed A, Kayeri BK (2019) Gastrointestinal parasites of dogs (Canis familiaris) in Maiduguri, Borno State, Northeastern Nigeria: Risk factors and zoonotic implications for human health, Veterinary World, 12(7): 1150-1153.

\begin{abstract}
Aim: This study was designed to investigate the prevalence, associated risk factors, and zoonotic implications of gastrointestinal parasites of dogs in Maiduguri, Borno State, Northeastern Nigeria.

Materials and Methods: A total of 200 rectal fecal samples were collected from dogs in Maiduguri for coprological examination using the saturated sodium chloride floatation technique. Detection of eggs or oocyst was done on the basis of keys of identification of parasites based on the morphology and size of eggs or oocyst.

Results: The prevalence of gastrointestinal parasites of dogs was 31.5\% (63/200) in Maiduguri. The prevalence of the infection was higher in young, male dogs kept outdoor in terms of age, sex, and management; the difference was statistically significant $(\mathrm{p}<0.05)$. The parasites detected in Maiduguri include Ancylostoma spp., Toxocara spp., Dipylidium spp., Isospora spp., and Taenia spp., with Ancylostoma spp. (16\%) having the highest prevalence rate.
\end{abstract}

Conclusion: Gastrointestinal parasites have high prevalence in Maiduguri and constitute potential risk to human health because all genera of parasites detected in the study area are of public health importance.

Keywords: coprological examination, gastrointestinal parasites, prevalence, zoonoses.

\section{Introduction}

Dogs (Canis familiaris) have a close association with humans, providing security, companionship, and dietary protein requirement [1]. Dogs have been associated with more than 60 zoonotic diseases [2]. Helminthosis reportedly takes significant veterinary and public health importance worldwide [3]. Different types of enteric parasites have been reported, but Ancylostoma caninum, Toxocara canis, Dipylidium caninum, Trichuris vulpis, and Echinococcus spp. are the most common [4]. These infections exert serious health challenges in dogs and a variety of clinical signs such as unthriftiness, malaise, irritability, mild diarrhea, melena, vomiting, anorexia, anemia, and poor hair coat, ranging from the type of infection and density of the parasite. However, the infection may be asymptomatic [5].

Dogs are the most common pet animals worldwide, with several reports incriminating dogs as host of various intestinal parasites of zoonotic importance. These

Copyright: Ezema, et al. Open Access. This article is distributed under the terms of the Creative Commons Attribution 4.0 International License (http://creativecommons.org/licenses/by/4.0/), which permits unrestricted use, distribution, and reproduction in any medium, provided you give appropriate credit to the original author(s) and the source, provide a link to the Creative Commons license, and indicate if changes were made. The Creative Commons Public Domain Dedication waiver (http://creativecommons.org/ publicdomain/zero/1.0/) applies to the data made available in this article, unless otherwise stated. infections are transmitted to humans through direct contact with infected dogs or exposure to environments contaminated with infected dog feces; alternatively, thelarvae can penetrate the skin of the susceptible host [6]. Other factors that also play a key role in the transmission of these infections to humans include wind, rain, arthropods, human, and vehicular traffic, which can aid the spread of the infective stages of parasites present in dog feces to human food and water sources. Children are most susceptible or at higher risk of exposure to the infection. Human infection with Toxocara spp. is asymptomatic, although some individuals may develop visceral larval migrans and ocular toxocariasis. Ancylostoma spp. have been reported as an etiological agent for cutaneous larval migrans and are associated with eosinophilic enteritis in humans [7].

In Nigeria, several reports exist on the endemicity of the infection in various states of the country, across various geographical distributions [8-10]. However, there is a paucity of information on the prevalence, risk factor, and public health significance of zoonotic infection to the human population especially when there is an increase in dog population for security, hunting, and breeding purposes, especially in developing nations.

This study aimed to provide information on gastrointestinal parasites of dogs and their risk factors and 
zoonotic implications to human health in Maiduguri. Data provided by this study will be utilized by practicing veterinarians who will be aware of parasites in their environment with its zoonotic significance which will guide their advice to dog owners, highlighting the dangers of these parasites and providing them with preventive measures which will, in turn, reduce the risk of zoonotic transmission.

\section{Materials and Methods}

\section{Ethical approval}

All samples were collected using standard sample collection without inflicting pain or harming the animals. The research was conducted after the approval of the Research and Ethics committee of University of Maiduguri, Nigeria.

\section{Study area}

This study was conducted in Maiduguri, the capital of Borno State, which lies in the Northeastern geopolitical zone. The state is situated within the semiarid zone of West Africa. It lies on latitude $11^{\circ} 5^{\prime} \mathrm{N}$ and $13^{\circ} 5^{\circ} \mathrm{E}$. It has a total area of 72,609 square $\mathrm{km}$. It is bordered by the Republic of Niger to north, Cameroon Republic to east, and Chad to northeast regions. The temperature ranges from $35^{\circ} \mathrm{C}$ to $40^{\circ} \mathrm{C}$ for most of the year. It is characterized by two distinct seasons: A short rainy season (June-September) and a long dry season (October-June) [11].

\section{Sample collection}

A total of 200 dogs were sampled in the study area; sampling was done based on convenience and prior to sample collection, owners' consent was obtained. A cross-sectional study was conducted from March to October 2018 on dogs with no bias to any of the risk factors. The dogs were properly restrained. About 5-10 g fecal samples were directly collected from the rectum using one of the gloved hands, while the other hand was used to support the caudoventral abdominal area, and the fecal samples were transferred to plastic containers. These containers were properly labeled with the age, sex, breed, and the management practice of the dogs. These samples were transported in an ice pack to the Department of Veterinary Parasitology and Entomology, University of Maiduguri, Borno State, Nigeria, for laboratory analysis.

\section{Laboratory analysis}

\section{Floatation technique}

About $2 \mathrm{~g}$ of feces was put into a universal bottle, and $5 \mathrm{ml}$ of floatation medium was added; in this study, the floatation medium was saturated salt solution with a specific gravity of 1.20 . The sample was broken and properly mixed with the floatation medium using a glass rod. It was sieved into a centrifuge tube and later placed on a tube rack. More of the medium was added until a convex meniscus was formed. A coverslip was placed on the filled tube and left to stand for 3-5 min. The coverslip was later placed on a glass slide and examined microscopically for eggs or oocysts. The eggs/oocysts were classified up to the genera level by keys for their identification based on their morphology and characteristics $[5,12]$. Each sample was categorized as positive if at least one egg or an oocyst was observed [13] by microscopy in the employed technique.

\section{Statistical analysis}

The prevalence was calculated for all data as the number of infected individuals divided by the number of examined individuals, and was expressed in percentage by multiplying by 100 . Chi-square test was employed to determine the statistical association between age, sex, breed, and management practice of dogs using GraphPad Prism 5.0 (San Diego, USA).

\section{Results}

Table-1 summarizes the overall prevalence of $31.5 \%$ in the study area and the prevalence of the infection based on associated risk factors. In terms of age, there was higher prevalence of the infection in the young (50.7\%) as compared to the adults (20.9), which was statistically significant. There was also a higher prevalence in males $(43.3 \%)$ than females (27.0), which was also statistically significant. Crossbreed dogs had a higher prevalence rate of $42.1 \%$ among both exotic and local breeds with $19.6 \%$ and $35.2 \%$, respectively. In terms of management, dogs that kept outdoor $(53.8 \%)$ had a higher prevalence rate as compared to those managed indoor $(12.8 \%)$; the difference was statistically different.

The prevalence of various genera of gastrointestinal infection in dogs is presented in Table-2. Six different genera of gastrointestinal parasites were observed in the study which include Ancylostoma spp. (16\%), Toxocara spp. (7.0\%), Dipylidium spp. (4.5\%), Isospora spp. (2.5\%), Taenia spp. (1.5\%), and Ancylostoma spp.

\section{Discussion}

This study revealed an overall prevalence of $31.5 \%$ of gastrointestinal parasitic infection in dogs from Maiduguri, Northeastern Nigeria. This study is in consonance with the findings in rural communities in Central Nigeria, [14] in Maiduguri [15], and in Venezuela [16], reported prevalence rates of $37.3 \%$, $38 \%$, and $34.8 \%$, respectively. However, the prevalence rate in this study is lower than the reports from Markudi [17], Zaria, [18] and Kaduna [19], reported prevalence rates of $73.7 \%, 62.7 \%$, and $93.8 \%$, respectively. These variations in the prevalence rate could possibly be due to sampling size, geographical variations, season of the study, access to veterinary services, the presence or absence of intermediate host, sampling protocols, demographic factors, and diagnostic techniques. Another key factor is the state of health of the dogs sampled in the study; for instance, Ogunkoya et al. [18] focused on clinically sick dogs presented to a veterinary teaching hospital, which 
Table-1: Prevalence and associated risk factors of gastrointestinal parasites of dogs (Canis familiaris) in Maiduguri, Borno State, Northeastern Nigeria.

\begin{tabular}{|c|c|c|c|}
\hline Risk factors & Number of examined dogs & Number of infected dogs & Prevalence (\%) \\
\hline \multicolumn{4}{|l|}{ Age } \\
\hline Young (<1 year) & 71 & 36 & $50.7^{\mathrm{a}}$ \\
\hline Adult ( $>1$ year) & 129 & 27 & $20.9^{b}$ \\
\hline Total & 200 & 63 & 31.5 \\
\hline \multicolumn{4}{|l|}{ Sex } \\
\hline Male & 83 & 36 & $43.3^{a}$ \\
\hline Female & 117 & 27 & $27.0^{\mathrm{b}}$ \\
\hline Total & 200 & 63 & 31.5 \\
\hline \multicolumn{4}{|l|}{ Breed } \\
\hline Exotic & 56 & 11 & $19.6^{\mathrm{a}}$ \\
\hline Cross & 19 & 08 & $42.1^{\mathrm{a}}$ \\
\hline Local & 125 & 44 & $35.2^{\mathrm{a}}$ \\
\hline Total & 200 & 63 & 31.5 \\
\hline \multicolumn{4}{|l|}{ Management } \\
\hline Owned (indoor) & 109 & 14 & $12.8^{\mathrm{a}}$ \\
\hline Stray (outdoor) & 91 & 49 & $53.8^{\mathrm{b}}$ \\
\hline Total & 200 & 63 & 31.5 \\
\hline
\end{tabular}

Number with same superscript in the $3^{\text {rd }}$ column did not differ statistically significantly $(p>0.05)$

Table-2: Prevalence of gastrointestinal infection by genera in dogs (Canis familiaris) in Maiduguri, Borno State, Northeastern Nigeria.

\begin{tabular}{lcc}
\hline Parasites & $\begin{array}{c}\text { Number of } \\
\text { positive samples }\end{array}$ & Prevalence (\%) \\
\hline Ancylostoma & 32 & 16 \\
spp. & 14 & 7.0 \\
Toxocara spp. & 9 & 4.5 \\
Dipylidium & 5 & 2.5 \\
spp. & 3 & 1.5 \\
Isospora spp. & 5 & \\
Taenia spp. & & \\
\hline
\end{tabular}

were most times diseased. The result of the study showed a higher prevalence rate of infection in the young $(50.7 \%)$ compared to the adults $(20.9 \%)$ where the difference was statistically significant $(\mathrm{p}<0.05)$. This agrees with the report of Mustapha et al. [15] but disagrees with the findings of Ehimiyein et al. [20] who reported a higher prevalence in adults. This could be associated to the fact that adults who are mostly carriers shed infective eggs after acquiring immunity from previous exposure of the infection; it is also a known fact that there is a possibility of transmission of helminths through the placenta or milk [5].

A higher prevalence rate of infection was observed in males $(43.3 \%)$ compared to females $(27.0 \%)$, which was statistically significant $(p<0.05)$. This is in consonance with the report of Mustapha et al. [15] and disagrees with the findings of Ehimiyein et al. [20] who reported a higher prevalence of the infection in female dogs. The high prevalence of the infection in males could be attributed to the fact the male dogs travel long distances, especially during breeding season in search of mates. Dogs kept indoors had a lower prevalence rate compared to those kept outdoor, which was statistically significant $(p<0.05)$, due to the tendency of the dogs to be exposed to natural infections, poor management of animal health, and high degree of environmental contamination. [17]. In terms of breed of the dogs, crossbreed dogs had the highest prevalence of infection; however, the difference was not statistically significant ( $p>0.05$ ).

The gastrointestinal parasites observed in this study were Ancylostoma spp., Toxocara spp., Dipylidium spp., Isospora spp., and Taenia spp. These parasites were similar to the reports from Maiduguri [15], Zaria [18], Kaduna Metropolis [19], and Zaria [20]. In this study, Ancylostoma spp. was the most prevalent species to cause infection, which is in consonance with the report of Mustapha et al. [15] but disagrees with the findings of Ehimiyein et al. [20] who reported Taenia spp. as the most prevalent species to cause infection. The higher prevalence of Ancylostoma spp. among all the other parasites suggests that the parasite is highly infective and efficiently transmitted; the ovum containing this species is maintained after being expelled in dog feces for a long period of time. This finding, therefore, highlights the importance of preventive measures because this parasite is of serious zoonotic implication causing eosinophilic enteritis and cutaneous larva migrans in humans. The high prevalence of Toxocara spp. has been associated with the ability of the adult parasite to shed a large quantity of infective eggs into the environment. The parasite is infective to humans causing visceral and ocular migrans $[4,6]$.

The results of this study clearly indicate that dog owners, especially their children, are at risk of the infection; this is because of their closeness to pets and the possibility of them to ingest sand.

\section{Conclusion}

This study clearly shows the endemicity of gastrointestinal parasites in Maiduguri, Northeastern Nigeria. The general public, especially dog owners and those who consume dog meat, fall within the high-risk category of acquiring the infection. Public 
health enlightenment campaigns by veterinarians with key focus on preventive measures such as regular deworming are required.

\section{Authors' Contributions}

KUE and SAM were involved in designing the research and drafting the manuscript, while MKZ, FK, AM, SMT, and BKK were involved in laboratory procedures. All authors read and approved the final manuscript.

\section{Acknowledgments}

The authors are grateful to the laboratory staff of the Department of Veterinary Parasitology and Entomology and Veterinary Teaching Hospital, University of Maiduguri, for their technical assistance. All resources required for the study were jointly funded by the authors.

\section{Competing Interests} interests.

The authors declare that they have no competing

\section{Publisher's Note}

Veterinary World remains neutral with regard to jurisdictional claims in published institutional affiliation.

\section{References}

1. Chidumayo, N.N. (2018) Epidemiology of canine gastrointestinal helminthes in Sub-Saharan Africa. Parasit. Vectors, 11(1): 100.

2. Johnson, S.A.M., Gakuya, D.W., Mbuthia, P.G., Mande, J.D. and Miangi, N. (2015) Prevalence of gastrointestinal helminthes and Management practices for dogs in the Greater Accra region of Ghana. Heliyon, 1(1): e23.

3. Sager, H., Moret, C.S., Grimm, F., Delpazes, P., Doherr, M.G. and Gottsetein, B. (2006) Coprological study on intestinal helminthes in Swiss dogs: Temporal aspects of anthelminthic treatment. Parasitol. Res., 98(4): 333-338.

4. Ayimode, B.A., Obebe, O.O. and Olayemi, E. (2016). Prevalence of potentially zoonotic gastrointestinal parasites in canine feces in Ibadan, Nigeria. Ghana Med. J., 50(4): 201-206.

5. Soulsby, E.J.L. (1982) Helminthes, Arthropods and Protozoa of Domestic Animals. $7^{\text {th }}$ ed. Bailliere, Tindall, London. p203-206.

6. Degefu, H., Tefera, A. and Yohannes, M. (2011) Zoonotic helminth parasites in fecal samples of household dogs in
Jimma town, Ethiopia. J. Public Health Epidemiol., 3(4): 91-94.

7. Prociv, P. and Croese, J. (1990) Human eosinophilic enteritis caused by dog hookworm Ancylostoma caninum. Lancet, 335(8701): 1299-1302.

8. Omudu, E.A. and Amuta, E.U. (2007) Parasitology and urban livestock farming in Nigeria: Prevalence of ova in fecal and soil samples and ectoparasites in Markudi. $J$. S. Afr. Vet. Assoc. 78(1): 40-45.

9. Ugbomoiko, U.S., Ariza, L. and Heukelbach, J. (2008) Parasites of importance for human health in Nigeria dogs: High prevalence and limited knowledge of pet owners. BMC Vet. Res., 4(1): 49-54.

10. Magaji, A.A., Mohammed, M.N., Saulawa, M.A. and Salihu, M.D. (2012) Survey of zoonotic gastrointestinal parasites of dogs (Canis familiaris) slaughtered at Zuru area, Kebbi State, Nigeria. Sci. J. Vet. Adv., 1(5): 132-136.

11. Borno State Ministry of Land and Survey (BMLS). Annual Weather Report. p30.

12. Bowman, D.D. (2009) Georgi's Parasitology for Veterinarians. $9^{\text {th }}$ ed. Saunders Company, Philadelphia, PA, USA. p419.

13. Lorenzini, G., Tasca, T. and De Carli, G.A (2007). Prevalence of gastrointestinal parasites in dogs and cats under veterinary care in Porto Alegre, Rio Grande do Sul, Brazil. Braz. J. Vet. Res. Anim. Sci., 44(2): 137-135.

14. Anosike, J.C., Zaccheus, V.O., Adeiyongo, C.M., Abanobi, O.C., Dada, E.O., Oku, E.E., Keke, I.R., Uwaezuoke, J.C., Amajuoyi, O.U., Obiokwu, C.E., Nwosu, D.C. and Ogbosu, F.I. (2006) Studies on intestinal worms (helminthiasis) infection in central Nigeria rural community. J. Appl. Sci. Environ. Mang., 10(2): 61-66.

15. Mustapha, F.B., Balami, S.B., Malgwi S.A., Adamu, S.G. and Wakil, Y. (2016) Prevalence of gastrointestinal parasites of hunting dogs in Maiduguri, Borno state. J. Agric. Vet. Sci., 9(8): 39-42.

16. Ramirez-Barrios, R.A., Barbora-Mena, G., Munoz, J., Angulo-Cubillan, F., Hernandez, E., Gonzalez, F. and Escolona, F. (2004) Prevalence of intestinal parasites in dogs under veterinary care in Maracaibo, Venezuela. Vet. Parasitol., 121(1-2): 11-20.

17. Mathew, T.T., Seer, I.J. and David, O.K. (2016) Prevalence of gastrointestinal helminthes infection of dogs in Markudi metropolis. Imp. J. Interdiscip. Res., 2(8): 42-49.

18. Ogunkoya, A.B., Useh, N.M. and Esievo, KA.N. (2006) The haemogram of dogs with gastrointestinal parasites in Zaria, Nigeria. J. Anim. Vet. Adv., 5(9): 782-785.

19. Umar, Y.A. (2009) Intestinal helminthosis in dogs in Kaduna metropolis, Kaduna state, Nigeria. Iran. J. Parasitol., 4(1): 34-39.

20. Ehimiyein, A.M., Maishanu, D.D. and Ehimiyein, I.O. (2018) Prevalence of gastrointestinal and hemoparasites in hunting dogs in Zaria, Nigeria. Sokoto J. Vet. Sci., 16(3): $55-60$. 